\title{
DENSIDADE DO SOLO E INFILTRAÇÃO DE ÁGUA COMO INDICADORES DA QUALIDADE FÍSICA DE UM LATOSSOLO VERMELHO DISTRÓFICO EM RECUPERAÇÃO ${ }^{(1)}$
}

\author{
Marlene Cristina Alves ${ }^{(2)}$, Luis Gustavo Akihiro Sanches Suzuki ${ }^{(3)} \&$ \\ Luiz Eduardo Akiyoshi Sanches Suzuki ${ }^{(4)}$
}

\begin{abstract}
RESUMO
A necessidade cada vez maior de alimentos, espaço e condições para sobrevivência faz com que as interferências antrópicas no ambiente sejam cada vez maiores. Solos intensivamente cultivados e de forma inadequada são degradados, assim como a construção de obras civis no meio rural sem atender à legislação pertinente tudo isso tem ocasionado problemas ao meio. Várias técnicas têm sido utilizadas para recuperar esses solos, sendo a principal delas a adição de MO. Contudo, informações sobre tempo para recuperação do solo, influência dos tipos de material orgânico e indicadores das alterações ainda são escassas. Este trabalho objetivou avaliar a recuperação das propriedades de um Latossolo Vermelho distrófico, de onde foi retirado material usado na terraplanagem e nas fundações da usina hidrelétrica de Ilha Solteira-SP, utilizando-se como indicadores de qualidade física a densidade do solo e a taxa de infiltração de água. A pesquisa foi feita em uma área onde se retirou uma camada de solo de $8,60 \mathrm{~m}$. O delineamento experimental foi em blocos casualizados, com cinco repetições e cinco tratamentos: testemunha (solo exposto sem técnicas de recuperação); espécie arbórea gonçaloalves (Astronium fraxinifolium Schott); gonçalo-alves + feijão-de-porco (Canavalia ensiformis); gonçalo-alves + nabo forrageiro (Raphanus sativus); e gonçalo-alves + gramínea (Brachiaria decumbens) + lodo de esgoto (60 $\left.\mathrm{Mg} \mathrm{ha}^{-1}\right)$. A densidade do solo foi avaliada antes e 356 dias após a implantação dos tratamentos, e a infiltração de água no solo foi determinada 188 dias depois da instalação dos tratamentos. Concluiu-se que ocorrem melhorias na qualidade do solo quando efetuado o seu preparo e a adição de lodo de esgoto e adubos verdes. A densidade do solo e a
\end{abstract}

\footnotetext{
${ }^{(1)}$ Recebido para publicação em julho de 2005 e aprovado em abril de 2007.

(2) Professora Livre Docente, Departamento de Fitossanidade, Engenharia Rural e Solos, Universidade Estadual Paulista UNESP. Campus de Ilha Solteira, CEP 15385-000 Ilha Solteira (SP). Bolsista do CNPq. E-mail: :mcalves@agr.feis.unesp.br

(3) Graduando do Curso de Agronomia, UNESP. Bolsista de iniciação científica/CNPq.

(4) Doutorando do Programa de Pós-Graduação em Engenharia Florestal, Universidade Federal de Santa Maria - UFMS. CEP 97105 900 Santa Maria (RS). Bolsista Capes. E-mail: luiseduardoass@zipmail.com.br
} 


\begin{abstract}
infiltração de água do solo são bons indicadores na avaliação dessas melhorias. As diferentes fontes de MO adicionadas ao solo e a ação do preparo deste interagem de maneira semelhante na recuperação da sua qualidade, porém a combinação lodo de esgoto mais braquiária proporciona maior altura de planta da espécie gonçalo-alves.
\end{abstract}

Termos de indexação: solo degradado, propriedades físicas do solo, adubação verde, lodo de esgoto.

\title{
SUMMARY: SOIL BULK DENSITY AND WATER INFILTRATION RATE AS INDICATORS OF PHYSICAL QUALITY RECOVERY OF AN OXISOL
}

\begin{abstract}
The increasing need for food, space and other conditions for human survival generate greater anthropic interferences with the environment. Intensively and improperly tilled soils are degraded and illegal civil construction in rural areas is causing problems. Different techniques are being used to ameliorate these soils, mainly by the addition of organic matter, but information on the time required for soil recovery, influence of the organic matter type and on indicators of soil alterations is still rare. Our study aimed to recover the properties of an Oxisol used for the leveling and implantation of the hydroelectric power station of Ilha Solteira, São Paulo. Bulk density and water infiltration rate were used as indicators of soil physical quality. The experiment was carried out in an area where a layer of $8.60 \mathrm{~m}$ of soil had been removed. The experiment had a randomized block design with five replicates and five treatments: control plot (open soil without amelioration); tree species Gonçalo-alves (Astronium fraxinifolium Schott); Gonçalo-alves + Canavalia ensiformis; Gonçalo-alves + Raphanus sativus; and Gonçalo-alves + Brachiaria decumbens + sewage sludge $\left(60 \mathrm{Mg} \mathrm{ha}^{-1}\right)$. Bulk density was evaluated before and 356 days after treatment installation, whereas soil water infiltration was determined 188 days after treatment installation. Improvements in the soil quality where obtained with tillage and sewage sludge and green manure application. Bulk density and soil water infiltration were useful as indicators of the improvements. Different sources of organic matter added to the soil and the action of soil tillage interact in a similar way in the recovery of soil quality, but the Gonçalo-alves trees grew highest with the combination of sewage sludge and Brachiaria decumbens.
\end{abstract}

Index terms: soil degraded, soil physical properties, green manure, sewage sludge.

\section{INTRODUÇÃO}

A atividade agrícola com ênfase na monocultura tem sido fator de aceleração da degradação do solo, geralmente ultimada pelo superpastejo e uso do fogo. Nesta fase inicia-se o processo de degradação da estrutura do solo e formação de voçorocas, agravando ainda mais o processo (Faria \& Franco, 1994). Souza \& Alves (2003a) mencionam que o preparo do solo, uma das principais operações de seu manejo, objetiva, entre outros, criar condições favoráveis ao crescimento e desenvolvimento das culturas, erradicar plantas invasoras e manejar resíduos culturais, aumentando a porosidade total na camada preparada. No entanto, seu principal efeito é refletido na perda da qualidade da estrutura do solo. Isso ocorre principalmente quando o preparo é executado com excessiva intensidade e em solo com condições inadequadas de umidade, levando à sua compactação.
Além da degradação do solo pelo uso agrícola, a construção de obras civis no meio rural também tem acarretado problemas de degradação ambiental. Com o desenvolvimento de novas técnicas, criam-se novas demandas e necessidades, como o aumento considerável no consumo de energia elétrica; em conseqüência, torna-se necessária a construção de novas usinas hidrelétricas. Tudo isso resulta nas chamadas "áreas de empréstimo", locais onde se retira material para complementar o volume de solo necessário à execução de terraplanagens e fundações (Lopes et al., 1994), e na inundação de grandes áreas, com a formação de lagos. No Estado de São Paulo existem 24 reservatórios com usinas hidrelétricas com capacidade instalada de geração de 10,2 milhões de quilowatts. Essas usinas hidrelétricas geram, aproximadamente, $95 \%$ da energia elétrica produzida no Estado e $20 \%$ de toda a produção brasileira. Ainda que a hidroeletricidade, como alternativa para 
produção de energia, possa ser considerada ambientalmente mais vantajosa em relação a outras opções, por utilizar um recurso natural renovável e não-poluente, a formação de reservatórios implica a ocorrência de diversos impactos ao ambiente (CESP, 1998).

Como conseqüência da construção de reservatórios, diversas áreas podem apresentar degradação, que se manifesta desequilibrando a litosfera (sobretudo em sua porção mais frágil, os solos), a hidrosfera e a biosfera (principalmente a cobertura vegetal). A recuperação desse tipo de ambiente é necessária para a minimização do impacto causado. As providências a serem tomadas podem visar à recuperação paisagística ou mesmo à manutenção do potencial produtivo.

Restaurar ecossistemas é a denominação atribuída ao desafio de, por meio de ações planejadas, recuperar a estrutura do solo e criar condições para que se restabeleçam, também, os processos ecológicos naturais de cada ecossistema. A degradação dos solos, com todas as suas implicações e conseqüências, tem resultado no desafio de viabilizar sistemas de produção que possibilitem maior eficiência energética e conservação ambiental, criando-se novos paradigmas tecnológicos na agricultura, baseados na sustentabilidade (Alves, 2001).

Segundo Ingaramo (2003), para avaliação da qualidade do solo, algumas das principais propriedades e fatores físicos considerados adequados para descrevêla são: porosidade, distribuição do tamanho de poros, densidade do solo, resistência mecânica, condutividade hidráulica, distribuição de tamanhos de partículas e profundidade em que as raízes crescem.

Stenberg (1999) enfatiza que nenhum indicador, individualmente, conseguirá descrever e quantificar todos os aspectos de qualidade do solo, pois deve haver relação entre todos os atributos do solo. Os critérios para seleção de indicadores relacionam-se principalmente com sua utilidade em definir os processos do ecossistema.

Para Doran \& Parkin (1994), os indicadores devem seguir os critérios de: envolver processos ocorrentes no ecossistema; integrar propriedades e processos físicos, químicos e biológicos; ser acessível e aplicável no campo; ser sensível a variações de manejo e de clima; e ser componente de banco de dados de solos, sempre que possível. Em física do solo, a qualidade está associada àquele solo que: permite a infiltração, retenção e disponibilização de água às plantas, córregos e subsuperfície; responde ao manejo e resiste à degradação; permite as trocas de calor e de gases com a atmosfera e raízes de plantas; e permite o crescimento das raízes (Reichert et al., 2003).

De acordo com Doran \& Parkin (1994), entre as propriedades físicas propostas como indicadores básicos na avaliação da qualidade do solo incluem-se a densidade e a taxa de infiltração de água no solo.
Segundo Alves \& Cabeda (1999), a infiltração de água é um dos fenômenos que melhor refletem as condições físicas internas do solo, pois uma boa qualidade estrutural leva a uma distribuição de tamanho de poros favorável ao crescimento de raízes e à capacidade de infiltração de água no solo. Com relação à densidade do solo, quando ocorre a degradação de sua estrutura, o efeito imediato é no seu aumento, acarretando a redução da macroporosidade. Alves (1992), Anjos et al. (1994) e Veiga et al. (1994) observaram, em solos degradados, que há relação inversa entre densidade do solo e porosidade total. Pelo exposto, sugerem-se a densidade e infiltração de água como indicadores da qualidade do solo em estudo.

A recuperação de áreas degradadas é possível, porém trata-se de um processo lento e difícil, sendo necessária a escolha de plantas com boa capacidade de crescimento e desenvolvimento nesses ambientes degradados, bem como o uso de práticas de manejo do solo que favoreçam sua recuperação. Também a adição de várias fontes de MO tem sido utilizada, com o objetivo de melhorar as propriedades do solo.

Diferentes espécies são utilizadas na recuperação de áreas degradadas. Neste estudo optou-se pela espécie nativa de cerrado conhecida como gonçalo-alves (Astronium fraxinifolium Schott), pois é pioneira e seletiva xerófita, encontrada em terrenos rochosos e secos, onde forma grupamentos descontínuos (Lorenzi, 1992; Aguiar et al., 2001), sendo agressiva e resistente à condições adversas.

Este trabalho teve como objetivo recuperar as propriedades físicas de um Latossolo Vermelho remanescente da área de onde se retirou solo, que foi usado na terraplanagem e fundação da usina hidrelétrica de Ilha Solteira-SP, com adubação verde, lodo de esgoto e plantas da espécie gonçalo-alves; como indicadores de qualidade física utilizaram-se a densidade do solo e a infiltração de água.

\section{MATERIAL E MÉTODOS}

A pesquisa foi instalada na área experimental da Universidade Estadual Paulista, campus de Ilha Solteira, situada no município de Selvíria-MS, cujas coordenadas geográficas são $51^{\circ} 22^{\prime}$ de longitude oeste e $20^{\circ} 22$ ' de latitude sul, com altitude de $327 \mathrm{~m}$. As médias anuais da região são: precipitação pluvial de $1.370 \mathrm{~mm}$, temperatura de $23,5^{\circ} \mathrm{C}$ e umidade relativa do ar entre 70 e $80 \%$. O solo original é um Latossolo Vermelho distrófico (Embrapa, 1999), cuja classe textural é franco-argilo-arenoso (665, 79 e $256 \mathrm{~g} \mathrm{~kg}^{-1}$ de areia, silte e argila, respectivamente).

O experimento foi instalado em uma área de onde se retirou uma camada de solo de $8,60 \mathrm{~m}$ de profundidade. Antes de sua implantação, que ocorreu em fevereiro de 2004, foi realizada a caracterização física e química do solo. O preparo da área constou de 
subsolagem, atingindo profundidade de 0,40 m, e revolvimento superficial com arado de aivecas (profundidade média de aração atingida de 0,30 m). Foi realizada a correção do solo, com a finalidade de elevar a saturação por bases a $70 \%$, aplicando-se 1,2 $\mathrm{Mg} \mathrm{ha}^{-1}$ de calcário dolomítico (PRNT $70 \%$ ). Todos os tratamentos para recuperação do solo incluíram a espécie arbórea nativa de cerrado gonçalo-alves (Astronium fraxinifolium Schott), com espaçamento entre as árvores de $3 \times 2 \mathrm{~m}$, perfazendo 25 plantas por tratamento e 500 plantas no experimento todo. Salienta-se que na testemunha o solo foi mantido exposto e sem técnica para recuperação; portanto, não foi plantada a espécie arbórea de cerrado.

O delineamento experimental adotado foi em blocos casualizados, com cinco tratamentos e cinco repetições. Cada parcela ocupou uma área de $96 \mathrm{~m}^{2}$ (12 x $\left.8 \mathrm{~m}\right)$. Os tratamentos foram os seguintes: testemunha (solo exposto sem técnicas de recuperação) - não se efetuou o preparo nem plantio da espécie arbórea; espécie arbórea gonçalo-alves (Astronium fraxinifolium Schott); gonçalo-alves + feijão-de-porco (Canavalia ensiformis); gonçalo-alves + nabo forrageiro (Raphanus sativus); e gonçalo-alves + gramínea (Brachiaria decumbens) + lodo de esgoto (60 $\left.\mathrm{Mg} \mathrm{ha}^{-1}\right)$.

As culturas usadas na adubação verde foram semeadas nas entrelinhas da espécie arbórea nativa, obedecendo-se ao espaçamento de 0,50 m para o feijãode-porco, semeadura a lanço para o nabo forrageiro (20 kg ha-1) e braquiária (16 kg ha-1).

O lodo de esgoto foi distribuído manualmente nas parcelas e, em seguida, incorporado com uma grade aradora. O lodo foi adquirido da Estação de Tratamento de Esgoto de Araçatuba (SANEAR), tratando-se de lodo de águas residuárias exclusivamente de esgotos domésticos, portanto, sem problemas de metais pesados (Quadro 1) (Suzuki \& Alves, 2005).

As plantas usadas na adubação verde foram manejadas na época de florescimento, sendo roçadas e deixadas na superfície do solo.

Antes da implantação da pesquisa e 356 dias depois de instalados os tratamentos, foram coletadas amostras com estrutura não-deformada nas camadas de: $0,00-0,05 ; 0,05-0,10 ; 0,10-0,20$ e $0,20-0,40 \mathrm{~m}$, para determinação da densidade do solo pelo método do anel volumétrico (Embrapa, 1997). A taxa de infiltração de água no solo foi avaliada aos 188 dias depois da implantação dos tratamentos, empregandose o método dos anéis concêntricos (Bertrand, 1965). A determinação da infiltração de água no solo foi avaliada nas parcelas que receberam os tratamentos e em uma área de vegetação original, de modo que possibilitasse a comparação com os tratamentos testados.

Aos 88 e 274 dias após a semeadura foi determinada a produção de biomassa verde e seca a partir de amostras coletadas em plantas contidas em 1,00 $\mathrm{m}^{2}$, de dois pontos da área útil da parcela. As amostras foram colocadas em estufa a $60-70{ }^{\circ} \mathrm{C}$, até atingirem massa constante, determinando-se assim a biomassa seca. Também se determinou a altura e o diâmetro das plantas de gonçalo-alves aos 87 e 230 dias após a implantação do experimento.

Os dados foram submetidos à análise de variância (ANOVA), e as médias, comparadas pelo teste de Tukey a $5 \%$.

\section{RESULTADOS E DISCUSSÃO}

Analisando estatisticamente os dados de densidade do solo, constata-se que houve interação significativa entre épocas de avaliação e tratamentos, bem como entre épocas e profundidades do solo. A densidade do solo estudado para as condições naturais, isto é, antes de retirar a camada de solo para o aterro, apresentou valores de $1,35 \mathrm{Mg} \mathrm{m}^{-3}$ na superfície (camada de 0,00-0,10 m) a 1,40 $\mathrm{Mg} \mathrm{m}^{-3}$ na subsuperfície (camada de 0,20-0,40 m) (Campos, 2004). Verificaram-se, após 356 dias de implantados os tratamentos, valores de densidade do solo que variaram de 1,56 a $1,59 \mathrm{Mg} \mathrm{m}^{-3}$, sendo para a testemunha ( $\mathrm{sem}$ tratamentos para recuperação) igual a $1,77 \mathrm{Mg} \mathrm{m}^{-3}$ (Quadro 2). Reichert et al. (2003) consideram $1,55 \mathrm{Mg} \mathrm{m}^{-3}$ como densidade crítica para o bom crescimento do sistema radicular em solos de textura média. Nesse caso, pela análise dos resultados dos tratamentos aos 356 dias, pode-se considerar a condição de densidade do solo próxima do limite crítico para o desenvolvimento das plantas. Portanto, o solo estudado, após um ano, está demonstrando recuperação de suas propriedades, pois em todos os tratamentos para recuperação houve diminuição significativa da densidade do solo. Salienta-se que

\section{Quadro 1. Caracterização química e conteúdo de água do lodo de esgoto utilizado}

\begin{tabular}{|c|c|c|c|c|c|c|c|c|c|c|c|c|}
\hline MO & $\mathbf{N}$ & $\mathbf{P}$ & $\mathbf{K}$ & $\mathrm{Ca}$ & $\mathrm{Mg}$ & $\mathrm{S}$ & $\mathbf{B}$ & $\mathrm{Cu}$ & $\mathbf{F e}$ & Mn & $\mathrm{Zn}$ & Conteúdo de água \\
\hline $\mathrm{g} \mathrm{dm}^{-3}$ & 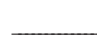 & 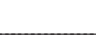 & g k & $s^{-1}$ & 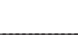 & - & 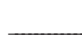 & 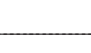 & $\mathrm{mg} \mathrm{kg}^{-1}$ & 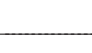 & 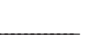 & $\mathrm{g} \mathrm{kg}^{-1}$ \\
\hline 200 & 71,26 & 18,79 & 15,14 & 11,06 & 3,44 & 7,78 & 16,4 & 160,0 & 960,6 & 115,7 & 583,5 & 0,85 \\
\hline
\end{tabular}


esse comportamento provavelmente está mais associado ao efeito da mobilização mecânica do solo, comportamento também verificado por Colodro (2005) para a densidade e porosidade num solo em recuperação.

Analisando os efeitos entre época de avaliação e profundidade, verificou-se maior densidade do solo na camada de 0,20-0,40 m, resultado que pode estar associado ao processo natural do solo ou ao acúmulo de pressões pelo tráfego de máquinas ou profundidade de trabalho dos implementos (Quadro 3).

Comportamento semelhante foi observado para infiltração de água (Quadro 4), sendo que as fontes de MO utilizadas na restauração do solo atuaram de forma semelhante até o momento.
Observa-se que a testemunha foi o tratamento que diferiu dos demais. Os tratamentos que estão como propostas de recuperação do solo não diferiram entre si e estão com valores de infiltração aproximadamente cinco vezes maior do que os da testemunha (solo degradado e exposto) e com capacidade de infiltração instantânea 50 \% menor do que a condição natural do solo (cerrado). Também nesse caso salienta-se que o comportamento verificado, provavelmente, está mais associado ao efeito da mobilização mecânica do solo (subsolagem) do que à adição de MO. Isso porque o tratamento que não recebeu nenhuma fonte de MO foi semelhante aos demais que a receberam. Portanto, a mobilização mecânica do solo, em curto prazo, resultou em valores de taxa de infiltração semelhantes aos dos tratamentos em que o solo foi mobilizado e

\section{Quadro 2. Interações entre épocas de avaliação e tratamentos em relação à densidade do solo}

Tratamento
Densidade do solo

Antes do início da pesquisa Após 356 dias

\begin{tabular}{llr} 
& \multicolumn{1}{c}{$\mathrm{Mg} \mathrm{m}^{-3}$} & \\
\cline { 2 - 3 } Testemunha & $1,64 \mathrm{Ab}^{(1)}$ & $1,77 \mathrm{Aa}$ \\
Gonçalo-alves & $1,66 \mathrm{Aa}$ & $1,56 \mathrm{Bb}$ \\
Gonçalo-alves + feijão-de-porco & $1,71 \mathrm{Aa}$ & $1,57 \mathrm{Bb}$ \\
Gonçalo-alves + nabo forrageiro & $1,71 \mathrm{Aa}$ & $1,59 \mathrm{Bb}$ \\
Gonçalo-alves + lodo de esgoto + braquiária & $1,68 \mathrm{Aa}$ & $1,58 \mathrm{Bb}$ \\
CV (\%) & & 7,78 \\
DMS (tratamento) & & 0,1117 \\
DMS (época) & & 0,0799
\end{tabular}

$\overline{{ }^{(1)} \text { Médias seguidas de letras iguais, maiúsculas na coluna e minúsculas na linha, não diferem estatisticamente entre si a } 5 \% \text { pelo }}$ teste de Tukey. CV = coeficiente de variação. DMS = diferença mínima significativa.

\section{Quadro 3. Interações entre épocas de avaliação e profundidades em relação à densidade do solo}

Densidade do solo

Camada
Após 356 dias

$\mathrm{m}$
$0,00-0,05$
$0,05-0,10$
$0,10-0,20$
$0,20-0,40$
CV (\%)
DMS (profundidade)
DMS (época)

(1) Médias seguidas de letras iguais, maiúsculas na coluna
teste de Tukey. DMS = diferença mínima significativa.

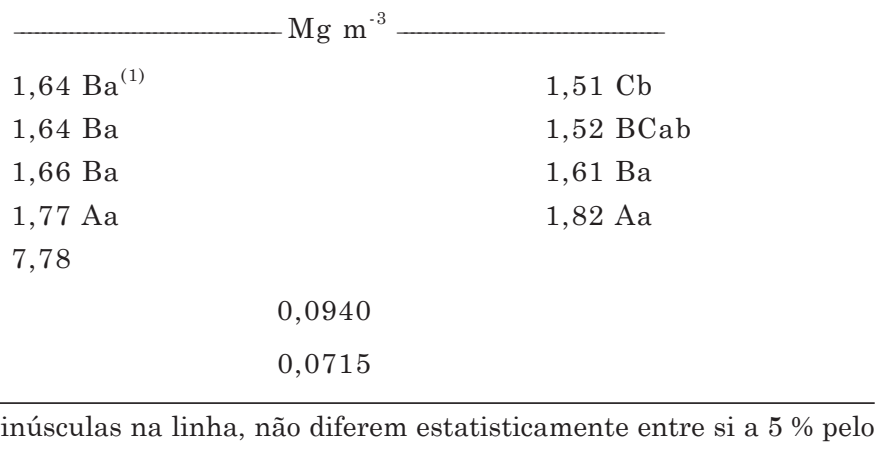


recebeu diferentes fontes de MO. A menor taxa de infiltração no solo degradado e sem técnicas para sua recuperação (testemunha) se deve ao processo de degradação da estrutura do solo (compactação), aliado à ausência de cobertura vegetal, no caso do solo exposto. Quando ocorre a degradação da estrutura do solo, há modificações no arranjamento de suas partículas, provocando diminuição no tamanho dos poros, especialmente daqueles de tamanho maior (macroporos), o que leva à redução na área da seção transversal para o fluxo de água, juntamente com percursos mais tortuosos para o movimento de fluido, afetando com isso o processo de infiltração (Souza \& Alves, 2003b).

Os valores mais altos da infiltração na área com cobertura vegetal devem, provavelmente, à influência que esta exerce sobre as propriedades físicas do solo. Sua influência manifesta-se essencialmente por meio da proteção de sua parte aérea contra o impacto das gotas de chuva e do efeito cimentante e estabilizador de substâncias orgânicas excretadas pelas raízes, principalmente aquelas sintetizadas pelos microrganismos do solo no processo de decomposição (Souza, 2000). Segundo esse autor, os valores da taxa constante de infiltração estão inversamente associados aos da densidade do solo, o que também foi verificado neste trabalho.

Com relação à infiltração acumulada, podem-se confirmar os resultados encontrados para o comportamento da taxa constante de infiltração nos diferentes tratamentos. A constatação de que a infiltração é maior na área com vegetação natural do que em solos cultivados foi feita nos trabalhos de Cavenage (1996), Suzuki et al. (2000) e Souza \& Alves (2003b).

A infiltração de água, bem como a densidade do solo, indicou diferenças nas condições físicas deste; observou-se que as fontes de MO utilizadas atuaram de forma semelhante na recuperação do solo avaliada pela taxa de infiltração de água.

A avaliação da qualidade do solo tem dimensão espacial e temporal. O intervalo entre medições para que o indicador avalie mudanças, portanto, depende do tempo necessário para que dado manejo produza alterações quantificáveis, e sua freqüência no espaço deve considerar as variações espaciais provocadas pelo solo (Reichert et al., 2003). Vale salientar que, após seis meses da combinação de prática mecânica mais uso de $\mathrm{MO}$, a mobilização do solo foi o fator que sobressaiu quanto ao aumento da infiltração de água, visto que no tratamento só com gonçalo-alves (sem adição de MO) a taxa de infiltração foi semelhante à dos outros tratamentos (com adição de MO), reforçando, portanto, a hipótese de que a mobilização do solo pelo preparo foi o fator que sobressaiu quanto à influência no aumento da taxa de infiltração, concordando com resultados de Colodro (2005).

Quanto às avaliações do diâmetro e altura das plantas de gonçalo-alves e da biomassa seca dos adubos verdes, houve concordância com o comportamento das condições físicas do solo observadas, sendo mais promissor o tratamento gonçalo-alves + lodo + braquiária.

Com 87 dias após o plantio das mudas de gonçaloalves, não se observaram diferenças estatísticas entre os tratamentos, mas houve tendência que pode ser comprovada na segunda avaliação, isto é, o tratamento com a adubação orgânica (lodo de esgoto) sobressaiu em relação aos demais quando se observou a altura de plantas (Quadro 5). Contudo, quanto ao diâmetro, ele apenas se diferenciou daqueles do tratamento com feijão-de-porco.

Até o momento, a combinação adubo orgânico (lodo de esgoto) e gramínea mostrou-se mais eficaz na melhoria e recuperação das condições físicas do solo, refletidas no maior crescimento da espécie arbórea de

\section{Quadro 4. Taxa constante de infiltração e infiltração acumulada no solo para os tratamentos estudados}

$\begin{array}{lcc} & \mathrm{cm} \mathrm{h}^{-1} & \mathrm{~cm} \\ \text { Testemunha } & 3,84 \mathrm{C}^{(1)} & 136,30 \mathrm{C} \\ \text { Vegetação original (Cerrado) } & 30,00 \mathrm{~A} & 586,04 \mathrm{~A} \\ \text { Gonçalo-alves } & 15,60 \mathrm{~B} & 478,08 \mathrm{~B} \\ \text { Gonçalo-alves + feijão-de-porco } & 16,32 \mathrm{~B} & 489,60 \mathrm{~B} \\ \text { Gonçalo-alves + nabo forrageiro } & 15,60 \mathrm{~B} & 499,68 \mathrm{~B} \\ \text { Gonçalo-alves + lodo + braquiária } & 13,68 \mathrm{~B} & 538,31 \mathrm{~B} \\ \text { CV (\%) } & 24,91 & 18,94 \\ \text { DMS (5\%) } & 6,2740 & 157,10\end{array}$

(1) Médias seguidas de letras iguais, na mesma coluna, não diferem estatisticamente entre si a $5 \%$ pelo teste de Tukey. $\mathrm{CV}=$ coeficiente de variação. DMS = diferença mínima significativa. 
cerrado. Avaretto et al. (2000) mencionam que as culturas forrageiras, gramíneas e leguminosas, em razão de suas características, têm sido usadas em programas de recuperação de áreas degradadas. Baruqui \& Fernandes (1985) afirmam que a cobertura vegetal melhora o teor de $\mathrm{MO}$ do solo, favorecendo a absorção de água e melhorando a estruturação do solo. O estabelecimento e o cultivo de plantas em solos degradados requerem também a utilização de insumos químicos e orgânicos (Leite et al., 1994). Segundo Martins et al. (1999), a associação entre o desenvolvimento vegetal e a atividade microbiana é fator importante na recuperação de solos degradados, pois, mesmo quando profundamente alterados, eles podem manter uma comunidade microbiana ativa.

A segunda avaliação das plantas foi feita no mês de outubro, antes do início das chuvas. As plantas, quando em período de estiagem, perdem algumas folhas; por isso, foram constatadas, quanto à altura delas, diferenças, porém não significativas, nos tratamentos nabo forrageiro + GA $(2 \mathrm{~cm})$ e feijão-deporco + GA $(1 \mathrm{~cm})$. Por outro lado, verifica-se que o diâmetro das plantas aumentou, comportamento que mostra que elas estão crescendo.

A produção de biomassa verde e seca, respectivamente de 2.876 e $352 \mathrm{~kg} \mathrm{ha}^{-1}$ do feijão-de-porco coletado aos 88 dias após a semeadura (Quadro 6), revela baixo rendimento, uma vez que Ceretta et al. (1994) encontraram valores de $6.052 \mathrm{~kg} \mathrm{ha}^{-1} \mathrm{em}$ um Argissolo Vermelho-Escuro de Santa Maria, RS. A braquiária coletada aos 88 dias após a semeadura produziu, respectivamente, 9.810 e $366 \mathrm{~kg} \mathrm{ha}^{-1}$ de biomassa verde e seca (Quadro 6), demonstrando melhor crescimento do que o feijão-de-porco.

Convém ressaltar que o nabo forrageiro apresentou boa germinação, porém não se cresceu, não sendo

Quadro 5. Altura e diâmetro de plantas de gonçalo-alves (GA), nos tratamentos estudados, aos 87 e 230 dias após o plantio

\section{Tratamento}

\section{Altura}

Diâmetro

\begin{tabular}{lll} 
& \multicolumn{2}{c}{87 dias após a semeadura } \\
\cline { 2 - 3 } Braquiária + lodo + GA & $23 \mathrm{~A}^{(1)}$ & $0,52 \mathrm{~A}$ \\
Nabo forrageiro + GA & $20 \mathrm{~A}$ & $0,44 \mathrm{~A}$ \\
Gonçalo-alves & $17 \mathrm{~A}$ & $0,40 \mathrm{~A}$ \\
Feijão-de-porco + GA & $17 \mathrm{~A}$ & $0,40 \mathrm{~A}$ \\
& & \\
Braquiária + lodo + GA & 230 dias após a semeadura \\
Nabo forrageiro + GA & $27 \mathrm{~A}$ & $0,84 \mathrm{~A}$ \\
Gonçalo-alves & $18 \mathrm{~B}$ & $0,66 \mathrm{AB}$ \\
Feijão-de-porco + GA & $17 \mathrm{~B}$ & $0,64 \mathrm{AB}$
\end{tabular}

(1) Médias seguidas de letras iguais, na mesma coluna, não diferem estatisticamente entre si a $5 \%$ pelo teste de Tukey.

Quadro 6. Rendimento de biomassa verde e seca de braquiária e feijão-de-porco, avaliado 88 dias após a semeadura

Adubo verde

Biomassa verde

Biomassa seca

$\begin{array}{lcc}\text { Braquiária } & 9.810,00 & 366,48 \mathrm{a}^{(1)} \\ \text { Feijão-de-porco } & 2.876,00 & 351,51 \mathrm{~b} \\ \text { CV (\%) } & & 2,28 \\ \text { DMS (5 \%) } & 14,3846\end{array}$

$\overline{(1)}$ Médias seguidas de letras iguais, na mesma coluna, não diferem estatisticamente entre si a $5 \%$ pelo teste de Tukey. CV = coeficiente de variação. DMS = diferença mínima significativa. 
possível a avaliação de sua biomassa. Possivelmente, esse adubo verde não está bem adaptado a regiões de clima quente, como essa onde foi instalado o experimento.

Decorridos 274 dias da semeadura, realizou-se nova avaliação da biomassa seca da braquiária, tendo seu rendimento aumentado 27 vezes, passando de 366,48 para $10.133,07 \mathrm{~kg} \mathrm{ha}^{-1}$. Bataglia et al. (1983) observaram produção de $48,7 \mathrm{~g}$ vaso $^{-1}$ de matéria seca de braquiária após a aplicação de $1.000 \mathrm{mg}$ de $\mathrm{N} \mathrm{e}$ seis cortes, tendo como fonte de $\mathrm{N}$ o lodo de esgoto. Carvalho et al. (1992) observaram que o fornecimento de $400 \mathrm{~kg} \mathrm{ha}^{-1}$ ano $^{-1}$ de $\mathrm{N}$ proporcionou produção de biomassa seca de aproximadamente $14.000 \mathrm{~kg} \mathrm{ha}^{-1}$. Portanto, os resultados alcançados para produção de biomassa seca da braquiária, condizentes com a literatura, significam que o solo está recuperando suas propriedades.

\section{CONCLUSÕES}

1. Ocorrem melhorias na qualidade do solo com o seu preparo e adição de lodo de esgoto e adubos verdes, e os indicadores utilizados (densidade e infiltração de água do solo) foram adequados para a avaliação dessas melhorias.

2. As diferentes fontes de MO estudadas mais a ação mecânica (preparo do solo), bem como a ação mecânica isolada, em curto prazo, interagem de maneira semelhante na recuperação da qualidade do solo.

3. A combinação lodo de esgoto mais braquiária proporciona maior crescimento da espécie gonçalo-alves.

\section{LITERATURA CITADA}

AGUIAR, A.V.; BORTOLOZO, F.R.; TEIXEIRA DE MORAES, M.L. \& EUSTÁQUIO DE SÁ, M. Determinação de parâmetros genéticos em população de gonçalo-alves (Astronium fraxinifolium) através das características fisiológicas da semente. Sci. Florestales, 60:89-97, 2001.

ALVES, M.C. Recuperação do subsolo de um Latossolo Vermelho usado para terrapleno e fundação da usina hidrelétrica de Ilha Solteira - SP. Ilha Solteira, Universidade Estadual Paulista, 2001. 83p. (Tese de Livre Docência)

ALVES, M.C. Sistemas de rotação de culturas com plantio direto em Latossolo Roxo: Efeitos nas propriedades físicas e químicas. Piracicaba, Escola Superior de Agricultura "Luiz de Queiroz", 1992. 173p. (Tese de Doutorado)

ALVES, M.C. \& CABEDA, M.S.V. Infiltração de água em um Podzólico Vermelho-Escuro sob dois métodos de preparo, usando chuva simulada com duas intensidades. R. Bras. Ci. Solo, 23:753-761, 1999.

ANJOS, J.T.; UBERTI, A.A.A.; VIZZOTO, V.J.; LEITE, G.B. \& KRIEGER, M. Propriedades físicas em solos sob diferentes sistemas de uso e manejo. R. Bras. Ci. Solo, 15:139-145, 1994.
AVARETTO, N.; MORAES, A.; MOTTA, A.C.V. \& PREVEDELLO, B.M.S. Efeito da revegetação e da adubação de área degradada na fertilidade do solo e nas características da palhada. Pesq. Agropec. Bras., 35:289-297, 2000.

BARUQUI, A.M. \& FERNANDES, M.R. Práticas de conservação do solo. Inf. Agropec., 11:55-68, 1985.

BATAGLIA, O.C.; BERTON, R.S.; CAMARGO, O.A. \& VALADARES, J.M.A.S. Resíduos orgânicos como fontes de nitrogênio para capim-braquiária. R. Bras. Ci. Solo, 7:277-284, 1983.

BERTRAND, A.R. Rate of water intake in the field. In: BLACK, C.A., ed. Methods of soil analysis. Madison, American Society of Agronomy, 1965. Part.1. p.197-208.

CAMPOS, F.S. Propriedades físico-químicas de um solo em recuperação sob sistema agrossilvopastoril. Ilha Solteira, Universidade Estadual Paulista, 2004. 61p. (Trabalho de Graduação)

CARVALHO, M.M.; MARTINS, C.E.; SIQUEIRA, C. \& SARAIVA, O.F. Crescimento de uma espécie de braquiária, na presença da calagem em cobertura e de doses de nitrogênio. R. Bras. Ci. Solo, 16:69-74, 1992.

CAVENAGE, A. Alterações das propriedades físicas e químicas de um Latossolo Vermelho-Escuro sob diferentes usos e manejos. Ilha Solteira, Universidade Estadual Paulista, 1996. 75p. (Trabalho de Graduação)

CENTRAIS ELÉTRICAS DO ESTADO DE SÃO PAULO CESP. Diretoria de Meio Ambiente. Recomposição vegetal. São Paulo, 1998. 11p.

CERETTA, C.A.; AITA, C.; BRAIDA, J.A.; PAVINATO, A. \& SALET, R.L. Fornecimento de nitrogênio por leguminosas na primavera para o milho em sucessão nos sistemas de cultivo mínimo e convencional. R. Bras. Ci. Solo, 18:215-220, 1994.

COLODRO, G. Recuperação de solo de área de empréstimo com lodo de esgoto. Campinas, Universidade Estadual de Campinas, 2005. 82p. (Tese de Doutorado)

DORAN, J.W. \& PARKIN, T.B. Defining and assessing soil quality. In: DORAN, J.W.; COLEMAN, D.C.; BEZDICEK, D.F. \& STEWART, B.A., eds. Defining soil quality for a sustainable environment. Madison, ASA, CCSA, SSSA, 1994. p.3-21.(SSSA Spec. Publ., 35)

EMPRESA BRASILEIRA DE PESQUISA AGROPECUÁRIA EMBRAPA. Centro Nacional de Pesquisa de Solos. Manual de métodos de análise de solos. 2.ed. Rio de Janeiro, 1997. 212p. (Embrapa-CNPS. Documentos, 1)

EMPRESA BRASILEIRA DE PESQUISA AGROPECUÁRIA . EMBRAPA. Sistema brasileiro de classificação de solos. Brasília, Embrapa Produção de Informações; Rio de Janeiro, Embrapa Solos, 1999. 412p.

FARIA, S.M. \& FRANCO, A.A. Espécies de leguminosas fixadoras de nitrogênio para revegetação de áreas degradadas. In: SIMPÓSIO SUL-AMERICANO, 1 ; SIMPÓSIO NACIONAL DE RECUPERAÇÃO DE ÁREAS DEGRADADAS, 2., Curitiba, 1994. Anais. Curitiba, UFPR/ Fundação de Pesquisas Florestais do Paraná 1994. p.481489. 
INGARAMO, O.E. Indicadores físicos de la degradación del suelo. La Coruña, Universidade da Coruña, 2003. 298p. (Tese de Doutorado)

LEITE, L.L.; MARTINS, C.R. \& HARIDASAN, M. Efeitos da descompactação e da adubação do solo na vegetação espontânea de uma cascalheira no Parque Nacional de Brasília. In: SIMPÓSIO SUL-AMERICANO, 1. SIMPÓSIO NACIONAL DE RECUPERAČ̃̃O DE ÁREAS DEGRADADAS, 2., Curitiba, 1994. Anais. Curitiba, UFPR/ Fundação de Pesquisas Florestais do Paraná, 1994. p.527-534.

LOPES, J.A.V. \& QUEIROZ, S.M.P. Rodovias e Meio Ambiente no Brasil: Uma resenha crítica. In: SIMPÓSIO SULAMERICANO, 1., SIMPÓSIO NACIONAL DE RECUPERAÇÃO DE ÁREAS DEGRADADAS, 2. Curitiba, 1994. Anais. Curitiba, UFPR/Fundação de Pesquisas Florestais do Paraná, 1994. p.75-90.

LORENZI, H. Árvores brasileiras. Piracicaba, Plantarum ,1992. $352 \mathrm{p}$.

MARTINS, C.R.; MIRANDA, J.C.C. \& MIRANDA, L.N Contribuição de fungos micorrízicos arbusculares nativos no estabelecimento de Aristida seti folia Kunth em áreas degradadas do cerrado. Pesq. Agropec. Bras., 34:665-674, 1999.

REICHERT, J.M.; REINERT, D.J. \& BRAIDA, J.A. Qualidade do solo e sustentabilidade de sistemas agrícolas. R. Ci. Amb., 27:29-48, 2003.

SOUZA, Z.M. \& ALVES, M.C. Propriedades físicas e teor de matéria orgânica em um Latossolo Vermelho de cerrado sob diferentes usos e manejos. Acta Sci., 25:27-34, 2003a.
SOUZA, Z.M. Propriedades físicas e químicas de um Latossolo Vermelho-Escuro de Selvíria (MS) sob diferentes usos e manejos. Ilha Solteira, Universidade Estadual Paulista, 2000. 127p. (Tese de Mestrado)

SOUZA, Z.M. \& ALVES, M.C. Movimento de água e resistência à penetração em um Latossolo Vermelho distrófico de Cerrado, sob diferentes usos e manejos. R. Bras. Eng. Agríc. Amb., 7:18-23, 2003b.

STENBERG, B. Monitoring soil quality of arable land: Microbiological indicators. Soil Plant Sci., 49:1-24, 1999.

SUZUKI, L.E.A.S.; ALVES, M.C. \& HIPÓLITO, J.L. Alteração na infiltração de água de um Latossolo Vermelho-Amarelo do noroeste do Estado de São Paulo sob sistema de preparo convencional. R. Iniciação Cient., 2:57-63, 2000.

SUZUKI, L.G.A.S. \& ALVES, M.C. Propriedades químicas de um solo em recuperação tratado com diferentes fontes de matéria orgânica. In: SIMPÓSIO NACIONAL DE RECUPERAÇÃO DE ÁREAS DEGRADADAS, 6.; CONGRESSO LATINO-AMERICANO SOBRE RECUPERAÇÃO DE ÁREAS DEGRADADAS, Curitiba, 2005. Anais. Curitiba, UFPR / Fundação de Pesquisas Florestais do Paraná, Sociedade Brasileira de Recuperação de Áreas Degradadas, 2005. p.1-13.

VEIGA, M.; BASSIL, L. \& ROSSO, A. Degradação do solo e da água: Manual de uso, manejo e conservação do solo e da água. 2.ed. Florianópolis, Secretaria da Agricultura e Abastecimento, 1994. 384p. 